\title{
Regular Consumption of a Balanced Salmon-Based Salty Snack Does Not Affect Energy Intake, Body Composition and Biochemical Parameters in Healthy Volunteers $\#$
}

\author{
Franca Marangoni $^{{ }^{*}}$, Stefano De Dionigi ${ }^{2}$, Paolo Magni ${ }^{3}$, Andrea Poli ${ }^{1}$ \\ ${ }^{1}$ Nutrition Foundation of Italy, Milan, Italy; ${ }^{2}$ Bolton Alimentari S.p.A., Cermenate, Italy; ${ }^{3}$ Department of Pharmacological and \\ Biomolecular Sciences-DiSFeB, University of Milan, Milan, Italy. \\ Email: "marangoni@nutrition-foundation.it
}

Received March 18 ${ }^{\text {th }}, 2013$; revised April 18 ${ }^{\text {th }}, 2013$; accepted April 25 $5^{\text {th }}, 2013$

Copyright (C) 2013 Franca Marangoni et al. This is an open access article distributed under the Creative Commons Attribution License, which permits unrestricted use, distribution, and reproduction in any medium, provided the original work is properly cited.

\begin{abstract}
An inverse relationship between meal frequency and body weight has been observed in several studies: however, little information is available on the effects of a snack consumption on energy and nutrient intakes in adults. In this study, 19 healthy volunteers consumed daily for 3 weeks, in a cross-over design, one of two isocaloric snacks (bread with salmon spread or bread with salami). Diet composition, anthropometrics, blood pressure, lipid and fatty acid profiles, fasting plasma glucose levels and high sensitivity $\mathrm{C}$ reactive protein (hs-CRP) were assessed at the beginning of the study and before and after each dietary period. The inclusion of a mid afternoon snack in the standard meal pattern (breakfast, lunch, dinner) was associated with a significant reduction in energy intake at dinner (the reduction being larger after the snack prepared with the salmon spread); the total daily caloric intake, however, was not changed by the snack consumption, since the snack caloric intake was fully compensated by the lower dinner energy intake. No significant change has been observed in any of the measured biochemical or anthropometric parameters, even if a trend toward a plasma hs-CRP reduction and toward a more favourable HUFA index was observed after the salmon spread snack consumption. These observations indicate that the regular consumption of a balanced mid afternoon snack has no adverse effects on energy intake and biochemical parameters of healthy adults with a moderately active lifestyle; the snack consumption results, however, in different distributions of the energy intake among meals. The snack composition (salmon or salami) may further influence these effects.
\end{abstract}

Keywords: Snack Consumption; Energy Intake; Meal Frequency

\section{Introduction}

The role of eating frequency, in particular of snack consumption, as part of a proper diet in association to a healthy lifestyle, undergoes a continuous debate among nutrition experts. On one hand, it is widely believed that a higher number of meals increases the risk of overeating and is associated to a low nutrient density of the diet [1]. These considerations have led to place snacking among the causes of obesity. On the other hand, results of epidemiological studies do not support the relationship between meal frequency and body weight, the latter being associated to total caloric intake more than to the number of meals. The distribution of the daily energy calories in

\#This study was supported by an unrestricted research grant from Bolton Alimentari S.p.A., Cermenate, Italy.

${ }^{*}$ Corresponding author.
3 main meals and 2 snacks (at mid morning and at mid afternoon) has in fact been shown to be effective in improving weight control and caloric management. Moreover in children, meal frequency has been associated to benefits for memory [2,3] and performance [4,5], and it has been proposed that, in specific physiological conditions, e.g. athlete and elderly, snack consumption can improve nutritional adequacy of the total diet [6,7] and help avoid to strain the gastrointestinal system [8].

On the basis of a balanced revision of these observations, the nutritional guidelines of national institutions and scientific societies agree in recommending the consumption of 3 main meals (breakfast, lunch and dinner) and 2 snacks for wellness maintenance, with the aim to reduce health related risk factors. In Italy, snacks must supply $5 \%-8 \%$ of the total daily caloric intake in the 
mid morning and $7 \%-10 \%$ in the mid afternoon according to a document of the Ministry of Health [9].

Intervention studies, performed on adult populations, have demonstrated in the human body the activity of metabolic pathways able to compensate the energy intake at subsequent meals, after the intake of balanced snacks $[10,11]$. However, most of these studies have tested foods generally considered healthy (nuts, dried plums, whole grains, fruits), showing functional effects of different components, like as proteins, antioxidants and fibre [12-15]. On the other hand, little information is available on the effects of foods consumed between meals.

This study aimed to evaluate the effects of the regular consumption of a proprietary salty snack, fish-based, in comparison with an Italian traditional snack, on the daily caloric intake, diet composition and anthropometric and biochemical parameters, in healthy volunteers.

\section{Methods}

Twenty healthy volunteers (ten males and ten females, aged $25-40 \mathrm{y}$; mean age $32.2 \pm 4.1 \mathrm{y}$ ) not overweight (mean BMI $24.3 \mathrm{~kg} / \mathrm{m}^{2}$ and $21.9 \mathrm{~kg} / \mathrm{m}^{2}$ for men and women, respectively) without metabolic syndrome or other metabolic diseases, have been recruited at the Department of Pharmacological and Biomolecular SciencesDiSFeB in Milan. The study protocol had been previously approved by the Local Committee on Ethics and all the volunteers signed written informed consent.

Before the beginning of the study, volunteers underwent a medical examination during which body weight, BMI, waist circumference, systolic (SBP) and diastolic blood pressure (DBP) were recorded; a blood sample was also obtained. In that occasion they also received a validated food frequency questionnaire, in order to assess their dietary habits. After a three weeks run-in period, during which they were invited to follow their usual diets without consuming mid afternoon snacks, they entered the intervention period, during which one of two isocaloric snacks, prepared with a white bread slice $(24 \mathrm{~g})$ and salmon spread (Rio Mare Patè, Bolton Alimentari S.p.A.) $(30 \mathrm{~g})$ or salami $(15 \mathrm{~g})$, were added to a free diet for three weeks. At the end of the first three weeks experimental period, after one week of wash-out with no between meal snacks, they introduced in their diet the other daily snack for three additional weeks, following a cross over protocol.

The following data have been collected during each medical examination (at the beginning of each time period: run-in, t0, phase I, wash out, phase II) after overnight fasting: anthropometrics, body composition (as percentage of body fat, lean mass, water) and resting energy expenditure by bioelectrical impedance, blood pressure, food consumption evaluated by 7-day diaries.
Blood samples collected from the antecubital vein have been used to assess the lipid profile and the fasting plasma glucose (FPG) concentrations with standardised methods, high sensitivity $\mathrm{C}$ reactive protein (hs-CRP) by turbidimetry, fatty acid profile by fast gascromatography of methyl esters [16].

Data were analyzed using an IBM SPSS (Statistical Package for Social Sciences) Version 19.0 software. Comparisons across diets were performed by using univariate analysis of variance (ANOVA). Differences between diets have been evaluate by using Student's $t$-test.

\section{Results}

The composition of the two snacks is shown in Table 1. Energy value ( $127 \mathrm{kcal}$ for salmon spread vs $122 \mathrm{kcal}$ for salami) and nutrient contents (as grams and En percentage) were similar among the two snacks.

The evaluation of food frequency questionnaires (data not shown) has confirmed the homogeneity of the study population, constituted by healthy adults, with moderately active lifestyles. Anthropometric data, blood SBP and DBP values throughout the study period are reported in Table 2. One male volunteer dropped out two weeks after the beginning of the first dietary intervention for health reason; as a consequence mean values for male volunteers are based on 9 subjects. Men, as expected, had higher weight, BMI, waist circumference, resting energy expenditure, body lean vs fat mass, SBP and DBP than women. Total cholesterol, triglycerides, FPG and hs-CRP (a marker of systemic inflammation) levels were lower (although not significantly) in the female group (Table $3)$, which showed significantly higher HDL $(\mathrm{p} \leq 0.05)$ and lower LDL cholesterol $(p \leq 0.05)$ at each visit. However, statistical analysis performed with Anova for

Table 1. Composition of the two snacks: salmon spread and salami.

\begin{tabular}{ccccc}
\hline Salmon spread snack & En (kcal) & Proteins & Carbohydrates & Fats \\
\hline $\begin{array}{c}\text { 30 g salmon spread } \\
\text { Rio Mare }\end{array}$ & 64 & 3.2 & 1.4 & 5.1 \\
24 g white bread & 63 & 2.1 & 11.0 & 1.2 \\
Total & 127 & 5.3 & 12.4 & 6.3 \\
Total kcal\% & & 17 & 39 & 44 \\
\hline $\begin{array}{c}\text { Salami snack } \\
\text { 15 g salami Milano } \\
\text { (3 slices) }\end{array}$ & 59 & 3.6 & 0.1 & 4.9 \\
24 g white bread & 63 & 2.1 & 11.0 & 1.2 \\
Total & 122 & 5.7 & 11.1 & 6.1 \\
Total kcal\% & & 19 & 36 & 45 \\
\hline
\end{tabular}


Table 2. Anthropometrics and blood pressure values in female $(n=10)$ and male $(n=9)$ volunteers according to snack consumption (Mean, SD).

\begin{tabular}{|c|c|c|c|c|c|c|c|c|c|c|}
\hline & \multicolumn{5}{|c|}{ Women } & \multicolumn{5}{|c|}{ Men } \\
\hline & \multirow{2}{*}{ Run-in } & \multicolumn{2}{|c|}{ Salami } & \multicolumn{2}{|c|}{ Salmon spread } & \multirow{2}{*}{ Run-in } & \multicolumn{2}{|c|}{ Salami } & \multicolumn{2}{|c|}{ Salmon spread } \\
\hline & & to & $3 \mathrm{wk}$ & to & $3 \mathrm{wk}$ & & to & $3 \mathrm{wk}$ & to & 3 wk \\
\hline \multirow[t]{2}{*}{ Body weight (kg) } & 56.71 & 56.89 & 57.24 & 57.02 & 56.93 & 74.09 & 74.49 & 74.11 & 74.27 & 74.06 \\
\hline & 7.84 & 7.97 & 8.43 & 8.06 & 7.90 & 10.44 & 10.57 & 10.25 & 10.80 & 10.82 \\
\hline \multirow[t]{2}{*}{ BMI $\left(\mathrm{kg} / \mathrm{m}^{2}\right)$} & 21.96 & 22.03 & 22.15 & 22.07 & 22.04 & 24.30 & 24.43 & 24.31 & 24.36 & 24.28 \\
\hline & 2.65 & 2.66 & 2.75 & 2.67 & 2.62 & 2.38 & 2.47 & 2.39 & 2.56 & 2.54 \\
\hline \multirow[t]{2}{*}{ Waist circumference (cm) } & 77.50 & 76.30 & 74.10 & 74.90 & 75.20 & 87.56 & 86.78 & 85.78 & 86.67 & 84.78 \\
\hline & 7.71 & 7.53 & 7.53 & 7.55 & 6.58 & 6.02 & 6.42 & 5.54 & 5.94 & 5.65 \\
\hline \multirow[t]{2}{*}{ Body fat (\%) } & 26.08 & 25.42 & 28.03 & 26.11 & 26.25 & 17.17 & 17.19 & 17.84 & 17.90 & 17.47 \\
\hline & 4.65 & 3.97 & 2.30 & 4.11 & 5.03 & 5.74 & 5.47 & 5.44 & 5.15 & 5.24 \\
\hline \multirow[t]{2}{*}{ Body water (\%) } & 53.92 & 54.41 & 52.43 & 53.90 & 54.20 & 60.43 & 60.34 & 59.93 & 59.81 & 60.20 \\
\hline & 3.40 & 2.88 & 1.71 & 2.98 & 2.85 & 4.20 & 3.96 & 3.96 & 3.74 & 3.82 \\
\hline \multirow[t]{2}{*}{ Lean mass (\%) } & 36.10 & 35.93 & 35.01 & 35.78 & 35.73 & 43.22 & 43.46 & 43.14 & 43.19 & 43.64 \\
\hline & 1.54 & 1.52 & 1.10 & 1.53 & 1.60 & 2.37 & 2.37 & 2.21 & 2.50 & 2.62 \\
\hline \multirow[t]{2}{*}{ REE (kcal) } & 1.340 .00 & 1.323 .67 & 1.379 .14 & 1.338 .67 & 1.325 .25 & 1.737 .00 & 1.716 .67 & 1.680 .11 & 1.740 .00 & 1.742 .14 \\
\hline & 80.43 & 85.51 & 85.77 & 85.77 & 64.96 & 161.96 & 174.69 & 251.78 & 170.42 & 189.87 \\
\hline \multirow[t]{2}{*}{$\mathrm{SBP}(\mathrm{mm} \mathrm{Hg})$} & 102.80 & 101.00 & 99.00 & 104.50 & 102.30 & 120.22 & 118.67 & 114.78 & 118.89 & 117.33 \\
\hline & 8.98 & 8.10 & 12.06 & 13.43 & 8.73 & 4.79 & 6.96 & 5.95 & 7.56 & 5.61 \\
\hline \multirow[t]{2}{*}{ DBP (mm Hg) } & 63.00 & 67.00 & 66.00 & 64.50 & 70.60 & 75.33 & 76.67 & 77.56 & 80.00 & 78.56 \\
\hline & 7.89 & 9.45 & 8.62 & 6.85 & 7.78 & 6.69 & 6.61 & 6.13 & 9.34 & 5.88 \\
\hline
\end{tabular}

Table 3. Lipid profile, glucose and hs-CRP levels according to snack consumption in female $(n=10)$ and $m a l e(n=9)$ volunteers according to snack consumption (Mean, SD).

\begin{tabular}{|c|c|c|c|c|c|c|c|c|c|c|}
\hline & \multicolumn{5}{|c|}{ Women } & \multicolumn{5}{|c|}{ Men } \\
\hline & \multirow{2}{*}{ Run-in } & \multicolumn{2}{|c|}{ Salami } & \multicolumn{2}{|c|}{ Salmon spread } & \multirow{2}{*}{ Run-in } & \multicolumn{2}{|c|}{ Salami } & \multicolumn{2}{|c|}{ Salmon spread } \\
\hline & & to & $3 \mathrm{wk}$ & $\mathrm{t} 0$ & $3 \mathrm{wk}$ & & t0 & $3 \mathrm{wk}$ & to & $3 \mathrm{wk}$ \\
\hline \multirow[t]{2}{*}{ Total Cholesterol (mg/dL) } & 185.80 & 200.50 & 193.00 & 196.80 & 192.50 & 201.67 & 208.89 & 207.11 & 202.00 & 201.33 \\
\hline & 25.44 & 24.95 & 22.48 & 22.06 & 18.60 & 35.76 & 37.84 & 45.22 & 33.80 & 29.74 \\
\hline \multirow[t]{2}{*}{ HDL Cholesterol (mg/dL) } & 73.70 & 77.00 & 76.20 & 77.40 & 76.50 & 60.78 & 62.11 & 59.44 & 60.00 & 60.33 \\
\hline & 17.92 & 19.32 & 19.13 & 18.73 & 21.52 & 11.96 & 13.16 & 19.46 & 11.68 & 11.07 \\
\hline \multirow[t]{2}{*}{ LDL Cholesterol (mg/dL) } & 100.50 & 107.40 & 101.50 & 102.60 & 100.50 & 125.33 & 127.56 & 125.33 & 125.89 & 121.67 \\
\hline & 26.51 & 26.13 & 22.99 & 20.40 & 16.71 & 27.40 & 29.46 & 31.21 & 28.41 & 20.75 \\
\hline \multirow[t]{2}{*}{ Triglycerides (mg/dL) } & 77.40 & 80.00 & 88.40 & 93.20 & 86.10 & 107.00 & 99.11 & 117.33 & 104.22 & 101.44 \\
\hline & 34.39 & 21.04 & 34.31 & 39.81 & 45.39 & 64.89 & 39.08 & 86.76 & 49.35 & 50.64 \\
\hline \multirow[t]{2}{*}{$\mathrm{FPG}(\mathrm{mg} / \mathrm{dL})$} & 87.70 & 88.70 & 87.70 & 86.60 & 85.70 & 94.56 & 90.11 & 91.44 & 92.00 & 91.67 \\
\hline & 6.29 & 5.66 & 3.30 & 7.34 & 7.32 & 13.16 & 11.08 & 9.81 & 11.66 & 8.86 \\
\hline \multirow[t]{2}{*}{ hs-CRP (ng/mL) } & 1.04 & 0.99 & 1.47 & 2.27 & 1.11 & 0.51 & 0.63 & 2.05 & 1.71 & 1.04 \\
\hline & 0.72 & 0.90 & 1.63 & 2.85 & 1.02 & 0.38 & 0.70 & 3.70 & 2.52 & 1.20 \\
\hline
\end{tabular}


repeated measures confirmed the lack of significant differences in anthropometrics, blood pressure and biochemical parameters measured at the first visit and at the subsequent time points, regardless of the sequence of snacks intake (e.g. salami and salmon spread or salmon spread and salami) both in the male and female group. hs-CRP showed an increase of borderline statistical significance at the end of the bread and salami snack period, and a decrease at the end of the bread and salmon spread phase ( $\mathrm{p}=0.064$ and 0.062 , respectively).

The diet nutrient composition was quite similar between men and women (Table 4). Total lipids exceed the recommended daily intake ( $30 \%$ of total energy) for both groups, while carbohydrates were well below the $55 \%$ -
$60 \%$ indicated in the guidelines. A slight reduction, although not significant, of calories from fat has been observed during the consumption of bread and salmon spread, independently from the snack sequence.

The inclusion of a snack in the mid afternoon after the run-in period, characterized by three main meals with a very light mid morning snack, impacted over the distribution of total energy intake among meals, as shown in Table 4: the caloric intake at dinner (the main daily meal) was significantly decreased, mostly with the snack prepared with bread and salmon spread in the male group.

No significant differences were observed in the fatty acid profile of blood lipids, following the two different snacks consumption (Table 5). However, the comparison

Table 4. Macronutrient composition of the diet at each study period and percentage distribution of the daily energy intake among meals in female $(n=10)$ and male $(n=9)$ volunteers (Mean, SD).

\begin{tabular}{|c|c|c|c|c|c|c|}
\hline & \multicolumn{3}{|c|}{ Women } & \multicolumn{3}{|c|}{ Men } \\
\hline & Run-in & Salami & Salmon spread & Run-in & Salami & Salmon spread \\
\hline \multirow[t]{2}{*}{ En (kcal) } & 1386.86 & 1321.59 & 1306.44 & 1559.97 & 1699.83 & 1561.52 \\
\hline & 250.55 & 206.32 & 251.09 & 272.17 & 196.44 & 233.39 \\
\hline \multirow[t]{2}{*}{ Proteins (g) } & 57.91 & 53.95 & 54.96 & 62.82 & 66.87 & 59.75 \\
\hline & 9.84 & 8.05 & 7.48 & 15.29 & 9.72 & 18.65 \\
\hline \multirow[t]{2}{*}{ Fats (g) } & 62.77 & 58.83 & 56.16 & 65.81 & 67.29 & 62.06 \\
\hline & 20.91 & 7.03 & 13.13 & 16.59 & 11.18 & 16.26 \\
\hline \multirow[t]{2}{*}{ Carbohydrates (g) } & 158.81 & 133.24 & 157.02 & 176.88 & 198.99 & 198.96 \\
\hline & 38.59 & 21.31 & 39.04 & 27.79 & 49.93 & 48.90 \\
\hline \multirow[t]{2}{*}{ Proteins (En \%) } & 17.49 & 17.03 & 17.68 & 16.55 & 16.66 & 15.18 \\
\hline & 1.77 & 1.34 & 2.85 & 1.69 & 2.14 & 2.74 \\
\hline \multirow[t]{2}{*}{ Fats (En \%) } & 41.25 & 42.18 & 39.16 & 38.74 & 37.41 & 36.12 \\
\hline & 7.01 & 2.32 & 5.87 & 5.49 & 5.70 & 7.11 \\
\hline \multirow[t]{2}{*}{ Carbohydrates (En \%) } & 43.50 & 40.75 & 45.77 & 44.36 & 45.34 & 48.58 \\
\hline & 6.01 & 2.21 & 4.59 & 6.53 & 7.58 & 8.72 \\
\hline \multirow[t]{2}{*}{ Breakfast (En \%) } & 16.20 & 14.78 & 16.00 & 14.22 & 14.56 & 17.11 \\
\hline & 5.27 & 7.08 & 4.71 & 7.56 & 8.26 & 8.52 \\
\hline \multirow[t]{2}{*}{ Mid morning snack (En \%) } & 4.00 & 5.00 & 3.33 & 5.40 & 4.25 & 2.00 \\
\hline & 2.83 & 4.24 & 3.21 & 2.97 & 2.06 & 1.00 \\
\hline \multirow[t]{2}{*}{ Lunch (En \%) } & 37.50 & 38.33 & 38.00 & 37.33 & 35.11 & 37.33 \\
\hline & 5.15 & 5.24 & 7.64 & 6.38 & 5.46 & 3.32 \\
\hline \multirow[t]{2}{*}{ Mid afternoon snack (En \%) } & . & 10.89 & 11.80 & & 8.44 & 8.22 \\
\hline & . & 2.98 & 3.29 & & 2.01 & 1.48 \\
\hline \multirow[t]{2}{*}{ Dinner (En \%) } & 54.70 & $38.11^{\mathrm{a}}$ & $38.00^{\mathrm{a}}$ & 50.56 & $43.22^{\mathrm{a}}$ & $38.33^{\mathrm{ab}}$ \\
\hline & 8.46 & 5.97 & 4.90 & 8.40 & 4.49 & 6.04 \\
\hline
\end{tabular}

${ }^{\mathrm{a}} \mathrm{p} \leq 0.001$ vs run-in; ${ }^{\mathrm{ab}} \mathrm{p} \leq 0.02$ salmon spread vs salami. 
Table 5. Fatty acid composition of whole blood fatty acids (\% of total fatty acids) according to snack consumption (Mean, SD).

\begin{tabular}{|c|c|c|c|c|c|c|c|c|c|c|}
\hline \multirow{3}{*}{$\begin{array}{c}\text { Fatty acids } \\
\qquad 16: 0\end{array}$} & \multirow{2}{*}{\multicolumn{2}{|c|}{ Run in }} & \multicolumn{4}{|c|}{ Salami } & \multicolumn{4}{|c|}{ Salmon spread } \\
\hline & & & \multicolumn{2}{|c|}{ t0 } & \multicolumn{2}{|c|}{$\mathrm{t} 21$} & \multicolumn{2}{|c|}{ to } & \multicolumn{2}{|c|}{$\mathrm{t} 21$} \\
\hline & 28.39 & 1.80 & 24.70 & 1.81 & 23.67 & 5.88 & 25.45 & 1.11 & 27.41 & 1.24 \\
\hline 18.0 & 12.99 & 0.95 & 11.11 & 0.86 & 11.84 & 1.20 & 11.38 & 1.06 & 11.47 & 0.88 \\
\hline $20: 0$ & 0.50 & 0.04 & 0.33 & 0.04 & 0.88 & 1.52 & 0.38 & 0.08 & 0.38 & 0.06 \\
\hline $22: 0$ & 1.31 & 0.07 & 0.90 & 1.14 & 1.22 & 0.64 & 1.04 & 0.14 & 0.89 & 0.14 \\
\hline $24: 0$ & 2.21 & 0.22 & 1.44 & 0.21 & 1.74 & 0.60 & 1.67 & 0.39 & 1.29 & 0.23 \\
\hline $16: 1$ & 0.60 & 0.05 & 1.10 & 0.52 & 0.74 & 0.43 & 1.13 & 0.52 & 0.82 & 0.38 \\
\hline $18: 1$ & 16.85 & 1.64 & 19.76 & 2.62 & 8.51 & 6.71 & 19.92 & 1.56 & 21.13 & 3.06 \\
\hline $18: 1 \mathrm{n}-7$ & 1.77 & 0.16 & 1.74 & 0.21 & 3.10 & 4.22 & 180 & 0.19 & 1.79 & 0.14 \\
\hline $20: 1$ & 0.18 & 0.03 & 0.18 & 0.03 & 0.12 & 0.05 & 0.18 & 0.03 & 0.15 & 0.03 \\
\hline $22: 1$ & 0.09 & 0.02 & 0.06 & 0.02 & 0.04 & 0.03 & 0.09 & 0.05 & 0.04 & 0.03 \\
\hline $24: 1$ & 2.90 & 0.40 & 2.24 & 0.70 & 2.34 & 0.63 & 2.49 & 0.65 & 2.10 & 0.50 \\
\hline $20: 3 n-9$ & 0.09 & 0.03 & 0.10 & 0.02 & 0.05 & 0.03 & 0.09 & 0.03 & 0.05 & 0.02 \\
\hline $18: 2 n-6$ & 16.37 & 1.68 & 20.40 & 2.10 & 19.18 & 3.54 & 19.74 & 1.80 & 19.21 & 1.78 \\
\hline $18: 3 n-6$ & 0.21 & 0.07 & 0.26 & 0.06 & 0.25 & 0.30 & 0.19 & 0.06 & 0.12 & 0.06 \\
\hline $20: 3 n-6$ & 1.48 & 0.28 & 1.47 & 0.32 & 4.06 & 3.04 & 1.42 & 0.42 & 1.15 & 0.22 \\
\hline $20: 4$ n-6 & 9.00 & 0.71 & 9.04 & 1.03 & 7.24 & 2.77 & 8.22 & 1.28 & 7.82 & 1.50 \\
\hline $22: 4 n-6$ & 1.17 & 0.28 & 1.21 & 0.36 & 0.90 & 0.47 & 1.16 & 0.32 & 0.79 & 0.24 \\
\hline $22: 5 n-6$ & 0.27 & 0.08 & 0.22 & 0.11 & 0.18 & 0.01 & 0.27 & 0.06 & 0.14 & 0.04 \\
\hline $18: 3 n-3$ & 0.17 & 0.08 & 0.22 & 0.11 & 0.67 & 1.00 & 0.19 & 0.08 & 0.19 & 0.06 \\
\hline $20: 5 n-3$ & 0.40 & 0.21 & 0.32 & 0.09 & 0.26 & 0.14 & 0.30 & 0.10 & 0.32 & 0.17 \\
\hline $22: 5 n-3$ & 0.77 & 0.11 & 0.80 & 0.11 & 0.74 & 0.24 & 0.73 & 0.13 & 0.62 & 0.12 \\
\hline $22: 6 n-3$ & 2.28 & 0.60 & 2.33 & 0.40 & 2.29 & 1.42 & 2.16 & 0.50 & 2.12 & 0.59 \\
\hline Saturated & 45.39 & 1.91 & 38.49 & 1.52 & 39.35 & 3.32 & 39.93 & 1.55 & 41.44 & 0.63 \\
\hline Monounsaturated & 22.41 & 1.66 & 25.09 & 2.87 & 24.85 & 3.13 & 25.62 & 1.51 & 26.03 & 2.67 \\
\hline Polyunsaturated & 32.20 & 1.40 & 36.42 & 2.68 & 35.80 & 3.46 & 34.46 & 1.39 & 32.53 & 2.78 \\
\hline Unsaturation Index & 122.52 & 5.04 & 133.98 & 6.17 & 130.43 & 10.64 & 127.69 & 4.94 & 121.54 & 7.63 \\
\hline Total n-6 & 28.49 & 1.34 & 32.66 & 2.75 & 31.80 & 3.29 & 31.00 & 1.28 & 29.23 & 2.38 \\
\hline Total n-3 & 3.62 & 0.88 & 3.66 & 0.51 & 3.95 & 1.42 & 3.37 & 0.66 & 3.25 & 0.73 \\
\hline$n-6 / n-3$ & 8.30 & 0.88 & 9.07 & 1.36 & 9.54 & 3.09 & 9.52 & 2.01 & 9.47 & 2.53 \\
\hline n-3 HUFA index & 22.45 & 5.22 & 22.50 & 4.10 & 20.94 & 3.38 & 22.40 & 4.06 & 23.55 & 4.26 \\
\hline
\end{tabular}


of the fatty acid composition of blood lipids from volunteers at the end of the two dietary periods shows a reduction of borderline significance $(p=0.052)$ for the $n-3$ HUFA index, a marker of the presence of long chain n-3 polyunsaturated fatty acids, EPA and DHA, vs. the long chain n-6 polyunsaturated fatty acids, after three weeks of salami snack consumption.

\section{Discussion and Conclusions}

Our data confirm that the addition of a regular mid afternoon snack (about $125 \mathrm{kcal}$ ) to the usual diet of healthy, young, physically active adults does not affect weight, BMI, fat mass, blood pressure, lipid profile, FPG. Interestingly, the total energy intake is also unaffected, indicating that the snack energy intake is fully compensated during the main meals. Energy intake at dinner is in fact significantly reduced by the introduction of a mid afternoon snack. This reduction seems to be greater if the snack is prepared with bread and salmon spread, suggesting a greater satiating effect of this snack, in accordance to published data on the satiating properties of fish [17]. This difference could also be explained, at least in part, by the different energy density of the two snacks, which was higher for salami (59 kcal in $15 \mathrm{~g}$ ) and lower for salmon spread (64 kcal in $30 \mathrm{~g}$ ).

Our data indicate that the consumption of a balanced snack between meals by healthy people does not affect weight (and hence BMI), body fat and the total caloric intake, but induces modifications in the caloric distribution among all the daily meals. These observations confirm those of other authors [18-20] supporting the correlations between weight and body fat and overeating in term of calories more than meal frequency or number of meals. Moreover, they suggest that consumption of a balanced snack, supplying an adequate caloric amount (about $12 \%$ of $2000 \mathrm{kcal}$, generally considered for an adult), involves metabolic responses able to regulate the total caloric intake and to avoid prompt changes in body composition. These effects, similar in men and women, seem to be independent of snack composition, food source (salami of animal origin and salmon spread from salmon and vegetable sources) and energy density.

Furthermore, this study allows to exclude effects of snack consumption on blood pressure, lipid profile and inflammation in the 3 weeks of observation. The slight improvement (of borderline significance) of hs-CRP (a well known marker of inflammation) associated with the consumption of the salmon spread snack may be attributed to the greater presence of unsaturated fats in this preparation (also indicated by the numerically higheralthough formally not significantly-n-3 HUFA index), being salmon the richest fish in $n-3$, than in that with salami, in which fats are mainly saturated. The same ex- planation could give reasons for the positive trends (again not significant) observed for HDL cholesterol after the salmon-based snack.

In conclusion, the regular consumption of one snack per day for 3 weeks has no adverse effects on the health of adults in good physical shape with a moderately active lifestyle and results in a different distributions of the energy intake among meals, including the reduction of the caloric content of dinner. This study has been performed with snacks supplying $10 \%-12 \%$ of total energy intake. The effects of snacks with higher or lower energy contents should be evaluated in specific trials.

Possible positive effects of the salmon-based snack, on fatty acid composition, satiety and hs-CRP, detected in this study but not supported by statistical significant differences with the control snack, need further confirmation from other studies with more selected products and larger cohorts.

\section{REFERENCES}

[1] F. Bellisle, R. McDevitt and A. M. Prentice, "Meal Frequency and Energy Balance," British Journal of Nutrition, Vol.77, No. S1, 1997, pp. S57-S70. doi:10.1079/BJN19970104

[2] S. Muthayya, T. Thomas, K. Srinivasan, K. Rao, A. V. Kurpad, J. W. van Klinken, G. Owen and E. A. de Bruin "Consumption of a Mid-Morning Snack Improves Memory But Not Attention in School Children," Physiology \& Behavior, Vol. 90, No. 1, 2007, pp. 142-150. doi:10.1016/j.physbeh.2006.09.025

[3] C. R. Mahoney, H. A. Taylor and R. B. Kanarek, "Effect of an Afternoon Confectionery Snack on Cognitive Processes Critical to Learning," Physiology \& Behavior, Vol. 90, No. 2-3, 2007, pp. 344-352. doi:10.1016/j.physbeh.2006.09.033

[4] D. Benton, O. Slater and R. T. Donohoe, "The Influence of Breakfast and a Snack on Psychological Functioning", Physiology \& Behavior, Vol. 74, No. 4-5, 2001, pp. 559571. doi:10.1016/S0031-9384(01)00601-1

[5] A. P. Smith and A. Wilds, "Effects of Cereal Bars for Breakfast and Mid-Morning Snacks on Mood and Memory," International Journal of Food Sciences and Nutrition, Vol. 60, No. S4, 2009, pp. 63-69. doi: $10.1080 / 09637480802438305$

[6] D. Shahar, I. Shai, H. Vardi and D. Fraser, "Dietary Intake and Eating Patterns of Elderly People in Israel: Who Is at Nutritional Risk?" European Journal of Clinical Nutrition, Vol. 57, No. 1, 2003, pp. 18-25.

doi:10.1038/sj.ejen.1601523

[7] C. A. Zizza, D. D. Arsiwalla and K. J. Ellison, "Contribution of Snacking to Older Adults' Vitamin, Carotenoid, and Mineral Intakes," Journal of the American Dietetic Association Vol. 110, No. 5, 2010, pp. 768-772. doi:10.1016/j.jada.2010.02.009

[8] N. R. Rodriguez, N. M. DiMarco and S. Langley, "Posi- 
tion of the American Dietetic Association, Dietitians of Canada, and the American College of Sports Medicine: Nutrition and Athletic Performance," Journal of the American Dietetic Association, Vol. 109, No. 3, 2009, pp. 509-527. doi:10.1016/j.jada.2009.01.005

[9] Ministero della Salute. Linee Guida per la Prevenzione Dell'Aterosclerosi. 2004

[10] M. Potier, G. Fromentin, J. Calvez, R. Benamouzig, C. Martin-Rouas, L. Pichon, D. Tomé and A. Marsset-Baglieri, "A High-Protein, Moderate-Energy, Regular Cheesy Snack Is Energetically Compensated in Human Subjects," British Journal of Nutrition, Vol. 102, No. 4, 2009 , pp. 625-631. doi:10.1017/S0007114509236026

[11] M. Viskaal-van Dongen, F. J. Kok and C. Graaf, "Effects of Snack Consumption for 8 Weeks on Energy Intake and Body Weight," International Journal of Obesty (London), Vol. 34, No. 2, 2010, pp. 319-326. doi:10.1038/ijo.2009.243

[12] L. Howarth, Y. Petrisko, A. Furchner-Evanson, T. Nemoseck and M. Kern, "Snack Selection Influences Nutrient Intake, Triglycerides, and Bowel Habits of Adult Women: A Pilot Study," Journal of the American Dietetic Association, Vol. 10, No. 9, 2010, pp. 1322-1327. doi:10.1016/j.jada.2010.06.002

[13] S. Zaveri and S. Drummond, "The Effect of Including a Conventional Snack (Cereal Bar) and a Nonconventional Snack (Almonds) on Hunger, Eating Frequency, Dietary Intake and Body Weight," Journal of Human Nutrition and Dietetics, Vol. 22, No. 5, 2009, pp. 461-468. doi:10.1111/j.1365-277X.2009.00983.x

[14] F. Folkvord, D. J. Anschütz, M. Buijzen and P. M. Valkenburg, "The Effect of Playing Advergames that Promote Energy-Dense Snacks or Fruit on Actual Food Intake among Children," The American Journal of Clinical Nutrition, Vol. 97, No. 2, 2013, pp. 239-245. doi:10.3945/ajen.112.047126
[15] T. J. Hastmann, M. Bopp, E. A. Fallon, R. R. Rosenkranz and D. A. Dzewaltowski, "Factors Influencing the Implementation of Organized Physical Activity and Fruit and Vegetable Snacks in the HOP'N After-School Obesity Prevention Program," Journal of Nutrition Education and Behavior, Vol. 45, No. 1, 2013, pp. 60-68. doi:10.1016/j.jneb.2012.06.005

[16] F. Marangoni, C. Colombo and C. Galli, "A Method for the Direct Evaluation of the Fatty Acid Status in a Drop of Blood from a Fingertip in Humans: Applicability to Nutritional and Epidemiological Studies," Analytical Biochemistry, Vol. 326, No. 2, 2004, pp. 267-272. doi:10.1016/i.ab.2003.12.016

[17] A. Ramel, D. Parra, J.A. Martinéz M. Kiely and I. Thorsdottir, "Effects of Seafood Consumption and Weight Loss on Fasting Leptin and Ghrelin Concentrations in Overweight and Obese European Young Adults," European Journal of Nutrition, Vol. 42, No. 2, 2009, pp. $107-$ 114. doi:10.1007/s00394-008-0769-9

[18] D. R. Keast, T. A. Nicklas and C. E. O'Neil, "Snacking Is Associated with Reduced Risk of Overweight and Reduced Abdominal Obesity in Adolescents: National Health and Nutrition Examination Survey (NHANES) 1999. 2004," The American Journal of Clinical Nutrition, Vol. 92, No. 2, 2010, pp. 428-435. doi:10.3945/ajen.2009.28421

[19] J. P. Mills, C. D. Perry and M. Reicks, "Eating Frequency Is Associated with Energy Intake but Not Obesity in Midlife Women," Obesity, Vol. 19, No. 3, 2011, pp. 552-559. doi:10.1038/oby.2010.265

[20] A. Dougkas, A. M. Minihane, D. I. Givens, C. K. Reynolds and P. Yaqoob, "Differential Effects of Dairy Snacks on Appetite, But Not Overall Energy Intake," British Journal of Nutrition, Vol. 108, No. 12, 2012, pp. 22742285 . 